\title{
Detection of Coronavirus in Simultaneously Collected Tear and Throat Swab Samples from the Patients with 2019- new Coronavirus Infection Disease: A Single Center Cross-sectional Study
}

\section{Ying Yan}

Department of Ophthalmology,Central Theater General Hospital, Wuhan

\section{Bo Zeng}

Department of Ophthalmology,Central Theater General Hospital, Wuhan

\section{Zhang Zhang}

Laboratory of Vaccine and Antibody Engineering, Beijing Institute of Biotechnology

\section{Cheng $\mathrm{Hu}$}

Department of Ophthalmology,Central Theater General Hospital, Wuhan

\section{Ming Yan}

Department of Ophthalmology,Central Theater General Hospital, Wuhan

\section{Bixi Li}

Department of Anesthesiology,Central Theater General Hospital, Wuhan

\section{Xiaopeng Zhang ( $\nabla$ zxp8565@aliyun.com )}

Laboratory of Vaccine and Antibody Engineering, Beijing Institute of Biotechnology

Xiao Chen ( $\square$ cxfn817@163.com )

Department of Ophthalmology,Central Theater General Hospital, Wuhan

\section{Research Article}

Keywords: Coronavirus, Tears, Infection

Posted Date: April 4th, 2020

DOI: https://doi.org/10.21203/rs.3.rs-21203/v1

License: (c) (i) This work is licensed under a Creative Commons Attribution 4.0 International License. Read Full License 


\section{Abstract}

Objecive: This study aimed to evaluate whether the coronavirus can be detected in the tears in the eyes of 2019- novel coronavirus (2019-nCoV) infected patients and compa re the detection consistency of two simultaneously collected samples, from the tears and throat swabs, of these patients.

Methods: A total of 35 diagnosis confirmed patients with 2019-nCoV infection disease,from January 26 to February 19,2020 , at central theater Wuhan general hospital of PLA, were included in this crosssectional case series study. The diagnosis was confirmed by both clinical and laboratory ways. Throat samples from all enrolled patients were collected with sampling swab, and simultaneously ,tear samples were collected $w$ ith sampling swab from 9 patients (No.1-9) and with Schirmer's strip from the remaining patients (No.10-35) (bilateral eyes for all patients). Sample collecting and testing were performed in three separate time points: first from patients No.1-9,second from $p$ atients No.10-29, and third from patients No.30-35. Reversetranscriptase-polymerase-chai n-reaction (RT-PCR) assay was performed by the same technician(Researcher Zhang), who was blind to the patients profile, within 4 hours after each collection.

Results: Among enrolled patients, 29 (No.1-29) had mild or moderate clinical symptoms and 6 (No.30-35) had severe symptoms. The mean time interval from the sample collection day to diagnosis confirmation day was $9.71 \pm 6.50$ days (ranged from 3 to 29 days). None of the patients had conjunctivitis. Nineteen out of $35(54.3 \%)$ throat samples presented positive Rt-PCR results. Three (no.13,21,31) out of $35(8.6 \%)$ tear samples presented positive RT-PCR results. Two(no.21,31) of these three patients were throat swab positive and one (No. 13) was negative. The consistency analysis indicated that tears and throat samples showed poor consistency (Kappa=-0.009, $\mathrm{P}=0.9$ ). The cycle threshold value (Ct-value) of tears samples collected by sampling swab was significantly higher than that by Schirmer's strip $(t=2.288, P=0.03)$.

Conclusion: In spite of the low 2019-nCoV positive detection rate of tear samples from 2019-nCoV infected patients, we cannot fully rule out the transmission by ocular surface. Whether tear testing can be used as an aid in judging of 2019-nCoV infection need further investigation.

Authors Ying Yan and Bo Zeng contributed equally to this study

\section{Introduction}

A novel coronavirus-infected disease was first reported in Wuhan, a city in central China in December 2019[1] . Up to March 10, 2020, a total of 80928 2019-nCoV infected cases in China have been confirmed[2].The outbreak of the disease has become a global health threat, and almost 24 countries and 5 continents have been afflicted with 2019-nCoV infected disease[3].

On January 7, 2020, the 2019 novel coronavirus (2019-nCoV) was isolated from the clinical specimens of bronchoalveolar lavage fluid and was confirmed as the cause of the disease[4],and a rapid human to human transmission has been confirmed [5]. Although respiratory droplets or contact has been identified 
as the route of human-to-human transmission [6], other potential routes including ocular surface secretions transmission have not been investigated[7].

It is reported that,the tears, being one of the body fluids, may potentially harbor the coronavirus. In the past, researchers detected many influenza viruses, including Ebola virus[8], severe acute respiratory syndrome coronavirus[9], and human immunodeficiency virus[10], in tears using polymerase chain reaction (PCR) technique. Therefore, we conducted this study to investigate whether 2019-nCoV can be detected in the tears of patients with 2019-nCoV infection.

\section{Methods}

This is a cross-sectional case series study. Thirty-five patients with confirmed 2019-nCoV infection by both the clinical way (includesymptoms, blood routine test and chest computed tomography) and the laboratory way (the revere-transcriptase-polymeras e-chain-reaction (RT-PCR) from throat swab sample), were recruited at the time of ad mission in the Central Theater General Hospital, Wuhan, China, from January 26 to F ebruary 19, 2020. Approval was obtained from the Ethics Committee of the Central T

heater General Hospital(No. [2020]009-1). The patients' signed consents were obtained.

Throat samples and tears of all patients were collected simultaneously. Throat samples were obtained by cotton swab scraping ministry of epiglottis,and tear samples from both eyes were collected with sampling swab (No.1-9) and with Schirmer's strip(No.10-35), respectively. For sampling swab, the samples were taken by putting sterile cotton wool sticks into the deep lower fornix of patients' eyes. For Schirmer's strip collection, a Schirmer's strip ( Schirmer Tear Test Strips; Liaoning Meizilin Pharmaceutical Co.,Ltd) was placed at the temporal canthus of each eye for $5 \mathrm{~min}$ without anesthetic and then removed from the eye.

The amount of wetting in millimeters was recorded by observing the location of the leading edge of moisture on the printed millimeter marks. All samples were placed into disposable virus sample tubes. Gloves were changed when collecting specimens in between patients to minimal contamination.

Samples were placed in $-4^{\circ} \mathrm{C}$ freezing box and transported immediately(within 1 hour) to the laboratory in the virology section of Academy of Military Medical Sciences. Rt-PCR

tests were performed within 4 hours after sample collection.

RT-PCR protocol: The samples were collected in an Eppendorf tube. Nucleic acid was extracted using LabServ Prefilled Viral Total NA Kit (Cat. KFRPF-805296, Fisher Scientific,

Shanghai, China) on KingFisher ${ }^{\text {TM }}$ Flex Purification System (Thermo Fisher Scientific, MA

USA). Basically, 300uL lysis buffer was added into the tube with the test paper, then mixed by vortex for 3 minutes, and the nucleic acid was purified following the instruction of the kit. The 2019-nCoV was tested 
by real-time RT-PCR using 2019-nCoV Nucleic acid Diagnostic Kit (Sansure Biotech, Changsha, Hunan Province, China), and two targets (open reading frame 1ab, nucleocapsid protein) were tested.

If either of the two targets (open reading frame $1 \mathrm{a}$ or $1 \mathrm{~b}$, nucleocapsid protein) was detected by specific real-time RT-PCR, the case would be considered as laboratory-confirmed. A cycle threshold value (Ctvalue) less than 39 was defined as a positive test, and a Ct-value of 39 or more was defined as a negative test.

\section{Results}

Among the 35 cases, 29 (No.1-29) were mild or moderate and 6 (No.30-35) were severe.

The mean age was $58.9 \pm 15.5$ years $\llbracket$ ranged from 20 to 89 years $\llbracket$ and $17(48.6 \%)$ were female. The mean time interval from the sample collection day to diagnosis confirmation day

was $9.71 \pm 6.50$ days (ranged from 3 to 29 days). Details of the characteristics of the patients were provided in Table 1.

All patients have been free of conjunctivitis since the onset and have not used any eye drops.

Nineteen out of 35 (54.3\%) patients presented positive Rt-PCR results. This nineteen patients consists of 13 mild or moderate and all of the 6 severe cases. The baseline characteristics stratified by positive and negative throat swab Rt-PCR results of the mild and

moderate patients $₫$ No. $1-29 \unrhd$ were compared in Table 2 . The average age of positive patients was larger than that of negative patients ( 63.5 vs. 50.4 years,$p=0.017)$. The average time

interval between the sample collection and diagnosis confirmation day of positive patients was shorter than that of negative patients ( $6.15 \mathrm{vs} .8 .44$ days, $P=0.034)$. There was no difference in sex区body temperature, cough, expectoration symptoms, degree of blood oxygen

saturation, and the use of antiviral drugs.

Three (no.13,21,31) out of 35 tear samples $(8.6 \%)$ presented positive RT-PCR results, 2 of which were throat swab positive and one (No. 13) was negative. Two of the these 3 were mild and moderate patients, both were 51 years old. And, the sample collection interval from diagnosis confirmed was 8 days and 7 days, respectively.(Table 3 ).

The consistency analysis indicated that tears and throat samples showed poor consistency. ( Kappa $=-$ $0.009, P=0.9)$.

Mean cycle threshold value (Ct-value) of tear samples collected by conventional 
sampling swab was significantly higher than that collected by Schirmer's strip ( $32.68 \pm 1.30 \mathrm{Vs}$ $31.39 \pm 1.45 \llbracket P=0.03)$.

The tear volumes of Schirmer's strip were negatively associated with the Ct-value for the 6 severe patients ( coefficient value $-0.928, \mathrm{P}=0.008$ ) (Table 4.).

\section{Discussion}

The transmission of 2019- novel coronavirus through eyes has recently attracted the researchers' attention. There were sporadic cases of conjunctivitis reported in infected patients whose conjunctival swabs were positive for nucleic acid of coronavirus[11-13]. However, for all infected patients, the positive rate of conjunctival swabs was very low, lower than that of throat swabs[11-13], which was consistent with the results of our study. It seemed that the possibility of virus existence in the ocular surface is low. However, more detailed analysis of the eye sample collection process and the laboratory nucleic acid test results can help to obtain more information.

In previous studies, conjunctival swabs were used to collect eye secretions including the tears, which were usually insufficient for test[14]. It was reported that the amount of tears collected by Schirmer's strip at one time was greater than that collected by other methods such as capillary tubes and surgical sponges [15].In the first nine patients (no.1-9) of this study, conjunctival swabs were used to collect samples and all the test results were negative. In the subsequent patients (no.10-29), Schirmer's strips were used to collect sample, and 2 samples were detected positive. This result suggested that the positive rate of the virus detection may be higher when Schirmer's strip was used. In addition, through the analysis of the volume of tear and the value of nucleic acid detection CT in 6 severe patients, it was found that there was indeed a quantity effect relationship between the two. This, to some extent, indicated that,the larger the amount of tear samples collected, the greater the probability of positive detection.

Another potential factor that affected the test results was the viral load in the sample. In theory, the more viral load, the higher the detection rate. The low positive rate of this study also indicated that the viral load in the ocular surface was relatively limited.

Due to the influence of multiple factors, the interpretation of the detection results should be more cautious-even throat swabs may have a high negative rate. In this study, throat swabs showed a positive detection rate of $54.3 \%$, which was far lower than that in recently published online study. Different from ours, the sputum (non throat swab) samples of patients were taken for nucleic acid detection, so a high positive detection rate (91.7\%) was obtained [13]. In practice, we found that most patients did not have sputum available. In addition to the way of sampling from bronchial secretion, the patients profile may also affect the nucleic acid detection results. For the patients with mild and moderate disease, we compared the baseline characteristics stratified by positive and negative throat swab Rt-PCR results (Table 2). Since the average age of the positive patients was greater than that of the negative patients, and the average interval between the sampled and diagnosis confirmed day for positive patients was shorter than that for negative patients,we suggested that the older the patients were, the earlier the 
detections were performed, the easier it was to detect nucleic acid fragments from throat swabs. However, for severe patients, because of their $100 \%$ positive rate, the possibility of the test results affected by the factors mentioned above should be small.

The fact that the consistency between the test results of throat swab and Schirmer's strip was low and that only two of three patients with tear Rt-PCR positive result had throat swab

positive result, suggested that the tear test results were not related to throat swab test results. Moreover, the result that one patient (No. 13) showed positive result of tear but negative of throat swab reminded us that Schirmer's strip detection may be used as an auxiliary means to identify patients with false negative throat swabs test result. Although the positive rate of tear test was very low, when facing this highly infectious disease, any additional screening for the control of disease transmission is of practical significance.

Limitation of this study was the relatively small sample size, especially the few severe patients included. In practice, in the face of the more infectious severe patients, sample collection performed in a single center had certain challenges. Another limitation also came from the small number of samples: no conjunctivitis patients could be included. Therefore, it was impossible to judge whether it was more likely to detect virus from the tears of conjunctivitis patients. Furthermore, we did not repeatedly collect and test samples, neither tears nor throat swab. Hence, we could not reduce the random errors occurred during the sample collection and testing process.

However, one of the advantages of this study was the simultaneous collection of throat swabs and tears from patients, which was helpful for us to compare the detection results of throat swab and tear. Another advantage came from the use of Schirmer's strip, which could collect larger volume of tear samples. From this perspective, Schirmer's strip outweighs the conjunctival swab. Most importantly, this study confirmed the practical value of Schirmer's strip by demonstrating the positive tear test result from patient no.13 who had negative throat test result.

In the future, we should pay more attention to the virus detection from ocular surface in different stages of the disease and different degrees of infection. Isolating the virus and determining the virus load, if exists, from the ocular surface, and investigating the existence of eye-body infection pathway will help us to clarify the human-human transmission route via eyes.

\section{Conclusions}

We cannot fully rule out the transmission by ocular surface. Whether tear testing can be used as an aid in judging of 2019-nCoV infection need further investigation. Moreover, we propose the use of Schirmer's strips that allow tear collection more efficiently.

\section{Declarations}




\section{Acknowledgment Section}

Thanks are due to Prof. Wei Chen for assistance with the experiments and Prof. Yanping Song for valuable discussion.

\section{This paper is supported by the projected of Health Commission Of Hubei Province}

\section{(NO.WJ2019H102)}

\section{Conflict of Interest}

The authors declare that they have no conflicts of interest.

\section{Statements}

1. All methods were carried out in accordance with relevant guidelines and regulations.

2. All patients provided written informed consent before participation in this study.

\section{References}

1. World Health Novel Coronavirus -

https://www.who.int/csr/don/12-january-2020-novel-coronavirus-china/en/.

2. World Health Tracking coronavirus: Map, data and timeline. https://bnonews.com/index.php/2020/01/the-latest-coronavirus-cases.

3. World Health Organization. Novel coronavirus (2019-nCoV): situation report-16-Erratum. https://www.who.int/docs/default-source/coronaviruse/situation-reports/20200205-sitrep-16ncov.pdf?sfvrsn=23af287f_4.

4. N. Zhu, D. Zhang, W. Wang, X. Li, B. Yang, J. Song, X. Zhao, B. Huang, W. Shi, R. Lu, P. Niu, F. Zhan, X. Ma, D. Wang, W. Xu, G. Wu, G.F. Gao, W. Tan, A Novel Coronavirus from Patients with Pneumonia in China, 2019, The New England journal of medicine 382(8) (2020) 727-733.

5. C. Wang, P.W. Horby, F.G. Hayden, G.F. Gao, A novel coronavirus outbreak of global health concern, Lancet (London, England) 395(10223) (2020) 470-473.

6. World Health Organization. Interim guidance 29 January

7. Zhang, Z. Kang, H. Gong, D. Xu, J. Wang, Z. Li, X. Cui, J. Xiao, T. Meng, W. Zhou, J. Liu, H. Xu, The digestive system is a potential route of 2019-nCov infection: a bioinformatics analysis based on single-cell transcriptomes, bioRxiv (2020) 2020.01.30.927806. 
8. G. Bausch, J.S. Towner, S.F. Dowell, F. Kaducu, M. Lukwiya, A. Sanchez, S.T. Nichol, T.G. Ksiazek, P.E. Rollin, Assessment of the risk of Ebola virus transmission from bodily fluids and fomites, The Journal of infectious diseases 196 Suppl 2 (2007) S142-7.

9. Tong, T.S. Lai, The severe acute respiratory syndrome coronavirus in tears, The British journal of ophthalmology 89(3) (2005) 392.

10. Han, N. Wu, W. Zhu, Y. Li, L. Zuo, J. Ye, Z. Qiu, J. Xie, T. Li, Detection of HIV-1 viruses in tears of patients even under long-term HAART, AIDS (London, England) 25(15) (2011) 1925-7.

11. Zhou, YY. Zeng, YQ. Tong, CZ. Chen, Ophthalmologic evidence against the interpersonal transmission of 2019 novel coronavirus through conjunctiva, medRxiv (2020) 2020.02.11.20021956.

12. Sun, X. Zhang, XH. Chen, LW. Chen, CH. Deng, XJ. Zou, WY. Liu, HM. Yu, The infection evidence of SARS-COV-2 in ocular surface: a single-center cross-sectional study.medRxiv (2020) 2020.02.26.20027938.

13. Xia J1, Tong J1, Liu M1, Shen Y1, Guo D1, Evaluation of coronavirus in tears and conjunctival secretions of patients with SARS-CoV-2 infection, Journal of medical virology 2020 Feb 26. doi:1002/jmv.25725.

14. Xia Jianhua,Tong Jianping,Liu Mengyun et Evaluation of coronavirus in tears and conjunctival secretions of patients with SARS-CoV-2 infection.[J] .J. Med. Virol., 2020, undefined: undefined.

15. Small D , Hevy J , Tang-Liu D . Comparison of Tear Sampling Techniques for Pharmacokinetic Analysis: Ofloxacin Concentrations in Rabbit Tears after Sampling with Schirmer Tear Strips, Capillary Tubes, or Surgical Sponges[J]. Journal of Ocular Pharmacology and Therapeutics, 2000, 16(5):439-446.

\section{Tables}

Table 1. Profile of 35 patients and viral detection results of throat and tears 


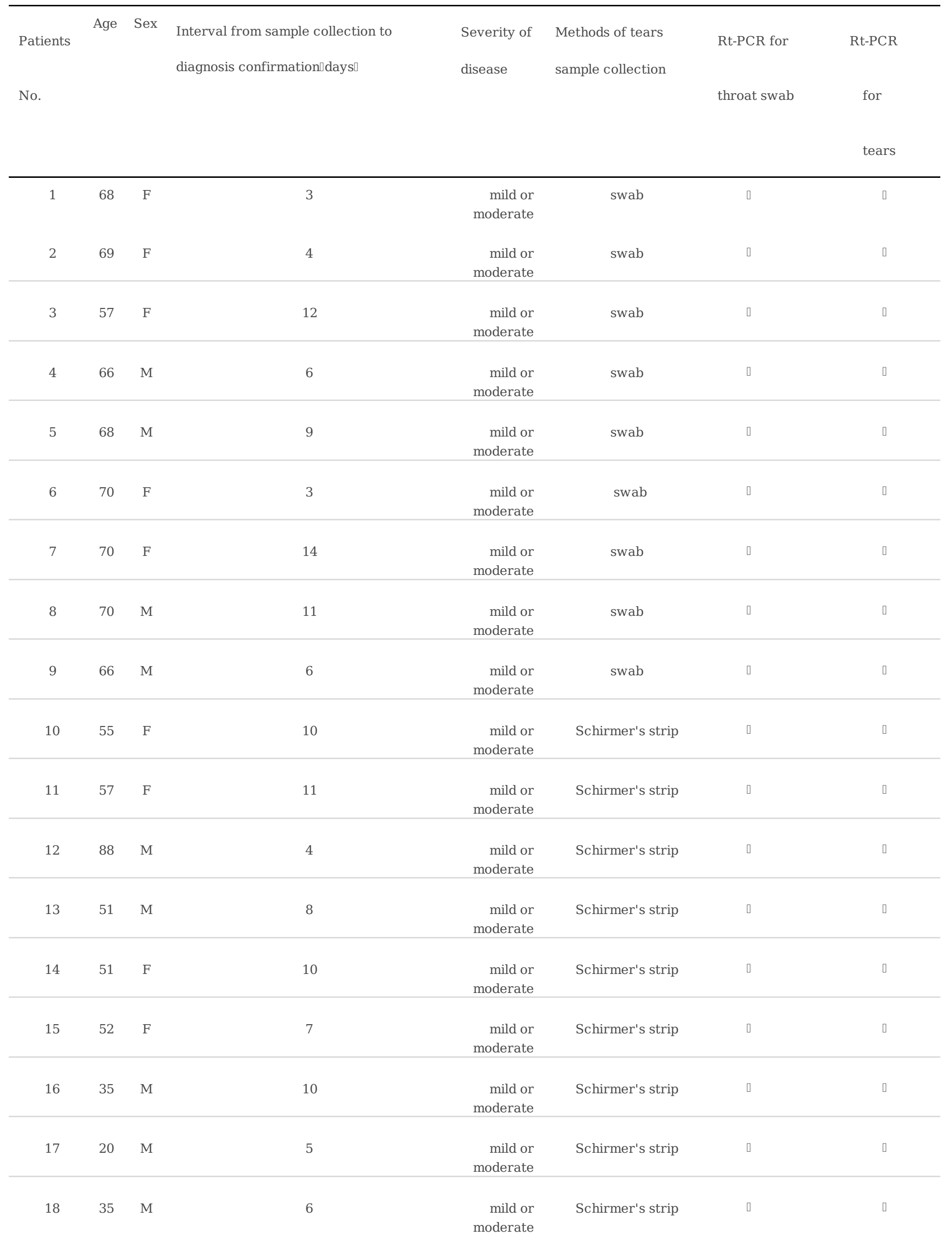


$19 \quad 56 \quad$ F

20

$63 \quad \mathrm{~F}$
6

10 mild or

moderate

mild or moderate

\begin{tabular}{|c|c|c|c|c|c|c|}
\hline 21 & 51 & $\mathrm{~F}$ & 7 & mild or moderate & Schirmer's strip & प० \\
\hline 22 & 31 & $\mathrm{~F}$ & 7 & mild or moderate & Schirmer's strip & पा \\
\hline 23 & 34 & M & 9 & mild or moderate & Schirmer's strip & प० \\
\hline 24 & 50 & M & 10 & mild or moderate & Schirmer's strip & प० \\
\hline 25 & 40 & M & 3 & mild or moderate & Schirmer's strip & प्र \\
\hline 26 & 57 & M & 7 & mild or moderate & Schirmer's strip & प्र \\
\hline 27 & 68 & $\mathrm{~F}$ & 7 & mild or moderate & Schirmer's strip & प्र \\
\hline 28 & 67 & $\mathrm{~F}$ & 6 & mild or moderate & Schirmer's strip & प्र \\
\hline 29 & 67 & $\mathrm{~F}$ & 4 & mild or moderate & Schirmer's strip & $0 \mathrm{Q}$ \\
\hline 30 & 68 & $\mathrm{~F}$ & 28 & severe & Schirmer's strip & पा \\
\hline 31 & 54 & M & 29 & severe & Schirmer's strip & प्र \\
\hline 32 & 89 & M & 21 & severe & Schirmer's strip & प० \\
\hline 33 & 78 & M & 24 & severe & Schirmer's strip & प० \\
\hline 34 & 72 & M & 11 & severe & Schirmer's strip & पा \\
\hline 35 & 68 & M & 12 & severe & Schirmer's strip & प० \\
\hline
\end{tabular}

Table 2. The baseline characteristics stratified by positive and negative throat swab Rt-PCR results of the mild and moderate patients₫No.1-29ם 


\begin{tabular}{|c|c|c|c|}
\hline & $\begin{array}{l}\text { Positive throat swab Rt-PCR } \\
\text { results } \\
\qquad(\mathrm{n}=13)\end{array}$ & $\begin{array}{l}\text { Negative throat swab Rt-PCR } \\
\text { results } \\
\qquad(\mathrm{n}=16)\end{array}$ & $\begin{array}{l}\mathrm{P} \\
\text { Value }\end{array}$ \\
\hline $\begin{array}{l}\text { Age(yrs) } \\
(\text { mean } \pm S D)\end{array}$ & $63.54 \pm 11.50$ & $50.38 \pm 15.37$ & $0.017^{*}$ \\
\hline Female,sex, no (\%) & $8(61.54)$ & $8(50.00)$ & 0.534 \\
\hline $\begin{array}{l}\text { The average interval between the sample collected and } \\
\text { diagnosis confirmed day(days) } \\
(\text { mean } \pm \text { SD) }\end{array}$ & $6.15 \pm 3.05$ & $8.44 \pm 2.45$ & $0.034^{*}$ \\
\hline $\begin{array}{l}\text { Body temperature }\left({ }^{\circ} \mathrm{C}\right) \\
(\text { mean } \pm \mathrm{SD})\end{array}$ & $36.35 \pm 0.19$ & $36.72 \pm 0.52$ & 0.054 \\
\hline Cough, no $(\%)$ & $4(30.77)$ & $7(43.75)$ & 0.474 \\
\hline $\begin{array}{l}\text { Expectoration symptoms } \\
\text { no (\%) }\end{array}$ & $1(7.69)$ & $3(18.75)$ & 0.390 \\
\hline $\begin{array}{l}\text { Degree of blood oxygen saturation, } \% \\
(\text { mean } \pm \text { SD) }\end{array}$ & $97.08 \pm 2.10$ & $97.19 \pm 1.56$ & 0.872 \\
\hline the use of antiviral drugs, no (\%) & 13(100) & $16(100)$ & 1.000 \\
\hline
\end{tabular}

* :p value of less than 0.05 was considered to indicate statistical significance.

Table 3.Profile of three cases with positive RT-PCR test result for tears samples 


\begin{tabular}{|c|c|c|c|}
\hline Patient no. & 13 & 21 & 3 \\
\hline Age(yrs) & 51 & 51 & 54 \\
\hline Sex & Male & Female & Male \\
\hline Date of confirmed CNIP & $\begin{array}{c}\text { February } \\
6,2020\end{array}$ & $\begin{array}{c}\text { February } \\
7,2020\end{array}$ & $\begin{array}{l}\text { January } \\
28.2020\end{array}$ \\
\hline Course of disease & Day 8 & Day 7 & Day 29 \\
\hline Severity of disease & $\begin{array}{c}\text { mild or } \\
\text { moderate }\end{array}$ & $\begin{array}{c}\text { mild or } \\
\text { moderate }\end{array}$ & severe \\
\hline \multicolumn{4}{|l|}{ Sample test result } \\
\hline Tears & positive & positive & positive \\
\hline Thoat & negative & positive & positive \\
\hline collection samples & $\begin{array}{c}\text { February } \\
14,2020\end{array}$ & $\begin{array}{c}\text { February } \\
14,2020\end{array}$ & $\begin{array}{c}\text { February } \\
26,2020\end{array}$ \\
\hline
\end{tabular}

\section{Key indication}

Cough

Expectoration symptoms

$\begin{array}{ll}+ & + \\ - & +\end{array}$

Body temperature $\left({ }^{\circ} \mathrm{C}\right)$

37.0

36.2

36.5

Degree of blood oxygen saturation,,$\% \square$

97

96

89

State of consciousness

awake state

awake state

coma

Using Extracorporeal Membrane

Oxygenation

Table 4. The relationship between a Ct-value and tears volume of 6 severe patients 


\begin{tabular}{ccc}
\hline Patients no. & $\begin{array}{c}\text { tears length of Schirmer's strip }(\mathrm{mm}) \\
\text { left eye/right eye }\end{array}$ & $\begin{array}{c}\text { Ct-value of tears sample } \\
\text { (RNase P) }\end{array}$ \\
\hline 30 & $5 / 7$ & 31.168 \\
31 & $20 / 25$ & 26.215 \\
32 & $12 / 12$ & 27.240 \\
33 & $6 / 7$ & 29.262 \\
34 & $8 / 9$ & 26.417 \\
35 & $7 / 6$ & 29.634 \\
\hline
\end{tabular}

The tears volume of Schirmer's strip were negatively associated with the Ct-value of tears sample of 6 severe patients.

(Spearman correlation coefficient, coefficient value $=-0.928, \mathrm{P}=0.008$ ). 